University of Chicago Law School

Chicago Unbound

\title{
Some Thoughts on the Real Estate Puzzle: Comment on Levmore, Commissions and Conflicts in Agency Arrangements: Lawyers, Real Estate Brokers, Underwriters, and Other Agents' Rewards
}

Alan O. Sykes

Follow this and additional works at: https://chicagounbound.uchicago.edu/journal_articles

Part of the Law Commons

\section{Recommended Citation}

Alan O. Sykes, "Some Thoughts on the Real Estate Puzzle: Comment on Levmore, Commissions and Conflicts in Agency Arrangements: Lawyers, Real Estate Brokers, Underwriters, and Other Agents' Rewards," 36 Journal of Law and Economics 541 (1993).

This Article is brought to you for free and open access by the Faculty Scholarship at Chicago Unbound. It has been accepted for inclusion in Journal Articles by an authorized administrator of Chicago Unbound. For more information, please contact unbound@law.uchicago.edu. 


\title{
SOME THOUGHTS ON THE REAL ESTATE PUZZLE: COMMENT ON LEVMORE, "COMMISSIONS AND CONFLICTS IN AGENCY ARRANGEMENTS: LAWYERS, REAL ESTATE BROKERS, UNDERWRITERS, AND OTHER AGENTS' REWARDS”*
}

\author{
ALAN O. SYKES \\ University of Chicago
}

$\mathbf{I}_{\mathbf{N}}$ "Commissions and Conflicts in Agency Arrangements," Saul Levmore explores unusual compensation structures that arise in a variety of agency relationships. Much of the paper focuses on the real estate industry, and on the 6 percent sales commission that so often governs residential real estate transactions. This emphasis is well placed as the real estate commission system does raise some puzzling issues.

The remarkable prevalence of the 6 percent commission, irrespective of the value of the property to be sold or the effort required to sell the property, has led other writers to wonder whether anticompetitive behavior is present and has stimulated antitrust enforcement activity directed against the industry. 'But anticompetitive explanations seem unsatisfying. The market structure of the industry seems ill suited to price fixing, with many agents serving most geographic areas and a relative ease of entry. Moreover, the 6 percent commission is found in widely disparate geographic markets, from Washington, D.C., to Chicago to Los Angeles, and it would seem odd that local real estate cartels had fixed the price at the same level everywhere. Finally, it is by no means impossi-

* Presented at the John M. Olin Centennial Conference in Law and Economics at the University of Chicago Law School, April 7-9, 1992. The author is Professor of Law, University of Chicago Law School. I wish to thank Michael Knoll for helpful comments.

${ }^{1}$ See, for example, Bruce M. Owen, Kickbacks, Specialization, Price Fixing and Efficiency in Residential Real Estate Markets, 29 Stan. L. Rev. 931 (1977); Norman G. Miller \& Peter J. Shedd, Do Antitrust Laws Apply to the Residential Real Estate Brokerage Industry? 17 Am. Bus. L. J. 313 (1979); Federal Trade Commission, 1-2 The Residential Real Estate Brokerage Industry (1983).

[Journal of Law \& Economics, vol. XXXVI (April 1993)]

(C)1993 by The University of Chicago. All rights reserved. 0022-2186/93/3601-0024\$01.50 
ble for a seller to negotiate an alternative compensation arrangement with an agent, and such arrangements are observed with some frequency where sellers actively pursue them. For these reasons, one is led to the alternative hypothesis that the 6 percent commission prevails in so many transactions because it is a reasonably efficient compensation device much of the time, emerging naturally from competitive forces. The challenge then is to articulate a convincing efficiency explanation.

Earlier writers focused on the question why a 6 percent commission should be paid on the sale of properties that are vastly different in price. At first blush, it seems unlikely that the effort required to sell a property increases in direct proportion to its value, and thus a commission that is a fixed percentage of the sales price would not appear to tailor compensation to the cost of selling. But the sellers of higher priced properties may require more services from their sales agents. The carrying costs of a property rise with its value, for example, which may justify greater effort to sell the property sooner rather than later. Alternatively, the market for more expensive properties may be thinner, so that more search effort is required to find a buyer. Plausibly, such considerations can explain why commissions might be a roughly constant fraction of value. A fixed percentage commission obviously achieves this proportionality and has the virtue (relative to, say, a flat fee) of providing some incentive for the agent to locate a buyer who will pay a higher price. ${ }^{2}$

As Levmore argues, however, it is hardly clear that these considerations provide a complete explanation for the popularity of the 6 percent commission. Surely, some properties can be sold more easily than others in the same price range, and the difference can be recognized ex ante. Further, if the compensation schedule is indeed important to agent incentives, one wonders why the fee schedule should be 6 percent of the total price-which seemingly affords the agent relatively little incentive for sales effort at the margin-in preference to some more steeply sloped schedule. Finding previous explanations lacking, therefore, Levmore proceeds to offer some additional reasons why the high degree of uniformity in commissions and the absence of greater rewards to the agent at the margin may be efficient, at least in a second-best sense. I wish to offer some further thoughts on these points as well.

\section{The Importance of the Low Marginal Commission}

If the parties cannot contract for optimal selling effort by the agent, the 6 percent commission structure might seem to create a whopping

\footnotetext{
${ }^{2}$ See Michael S. Knoll, Uncertainty, Efficiency and the Brokerage Industry, 31 J. Law \& Econ. 249 (1988); Wayne Carroll, Fixed-Percentage Commissions and Moral Hazard in Residential Real Estate Brokerage, 2 J. Real Est. Fin. \& Econ. 349 (1989).
} 
moral hazard problem. The joint optimum requires that a dollar of effort be expended at the margin whenever it yields at least a dollar of additional expected revenue on the sale (putting aside risk aversion). But the agent's private optimization problem might be thought to yield the level of effort at which an extra dollar spent on selling yields an extra dollar of expected sales revenue times the commission rate, typically only 6 percent of the total revenue gain as noted. Agency agreements that reward the agent with a much higher percentage of marginal sales revenue through a (perhaps sharply) nonlinear, upward-sloping commission schedule could reduce this problem, and their absence in practice might seem puzzling.

Levmore explains the absence of higher marginal commissions partly by considerations of agent risk aversion, partly by an appeal to the transaction costs of identifying the appropriate nonlinear fee schedule on a case-by-case basis, partly by the importance of providing the seller with adequate incentives for property maintenance after the sales agreement is signed, and partly by the possibility of conflicts among principals that would arise if their joint agent received different commissions on different properties (an argument discussed further below). I do not dispute that each consideration is quite plausibly relevant. Instead, I wish to emphasize that the description of the moral hazard problem above is mistaken and that the agent's private optimization problem does not in general allow the agent to select the level of sales effort where the marginal cost of effort equals the marginal gain in expected sales revenue times the commission rate. Once the agent's problem is appropriately reconceptualized, the moral hazard problem may become considerably less acute, although its magnitude remains an empirical question.

In particular, an important aspect of the real estate agency relationship is that the agent does not have the power to accept an offer from a buyer. Rather, the agent simply presents offers to the principal who can then accept or reject them. The exception is the full price offer, at which a refusal of the principal to accept becomes a breach of the agency agreement. Further, the agent receives no compensation at all under the typical arrangement unless an offer is accepted. Under these conditions, the agent receives nothing until the agent identifies a buyer who is willing to pay an amount equal to the principal's reservation price or the listing price, whichever is less. This fact plainly allows principals to induce greater effort by agents than they would exert if they had the power to accept offers. In certain limiting cases, it even allows the principal to induce first best effort, and those limiting cases may not be too wildly at variance with reality.

To give a simple illustration, suppose that the best offer for a property, $R$, is a random variable that depends on agent sales effort, $e$, with greater effort yielding a higher expected best offer. Effort is unobservable and 
thus cannot be specified in the contract. It is supplied at constant cost to the agent of $c$. Assume for simplicity that only one distribution of offers can be purchased and that the draw from that distribution does not occur until the agent has chosen $e$. The principal and agent are risk neutral and employ a fixed percentage commission arrangement in which the agent's commission is $\alpha$ times the sales price for any accepted offer. Finally, let $K$ be the value of the property to the principal in its current use and assume for now that the principal cannot credibly commit to reject offers at least equal to $K$ plus the commission that would be owed (the principal accepts a break even offer). Let $B$ denote the break-even offer, so that $B=K+\alpha B$. The jointly optimal level of effort must maximize the expression

$$
\int_{R \geq K}(R-K) d F(R \mid e)-e c .
$$

By contrast, the agent will choose $e$ to maximize

$$
\alpha \int_{R \geq B} R d F(\mathrm{R} \mid \mathrm{e})-e c .
$$

The two expressions differ, and a perfect alignment of the interests of principal and agent is plainly absent. But the effort level that the agent will select must take account of the need to find a buyer who will offer at least $B$, and this fact can motivate considerably greater sales effort than the agent would exert otherwise.

To make the point as simply as possible, consider the limiting case in which $F(R \mid e)$ collapses to a spike (that is, think of $R$ as a deterministic function of $e$, written $R(e)$, and assume it to be strictly concave.) Assume that there exists a level of effort that will surely yield an offer of $B$ which, by assumption, the principal will accept in indifference. Call that level of effort $e_{B}$ and assume that the agent prefers to expend that level of effort and earn $\alpha B$ than to earn nothing. Assume further that the level of effort which represents the solution to $a R^{\prime}(e)=c$, the level of effort that the agent would choose if the agent had the power to accept offers, is less than $e_{B}$. Then, the agent will clearly choose $e_{B}$. A moral hazard problem still arises to the degree that the jointly optimal level of effort $e^{*}$, which satisfies $R^{\prime}\left(e^{*}\right)=c$ if an interior solution, is greater than $e_{B}$. If the principal can somehow commit to reject offers below $R\left(e^{*}\right)$, however, the moral hazard problem can be eliminated in this limiting case. All the principal need do is set $\alpha$ high enough that the expenditure of $e^{*}$ is profitable for the agent.

Under more general and realistic assumptions about $F(R \mid e)$, the analysis becomes more complex, and I shall not burden the reader with a complete discussion of the general case. Suffice it to say that, because of the principal's ability to set a credible reservation price-and $B$ as defined above is surely credible in every case-the nature of the agent's 
private optimization problem changes profoundly. And, going beyond this simple model, if the principal can credibly insist on the price that is jointly optimal (that represents the joint-maximizing reservation price in an optimal search problem), it is no longer clear that a serious moral hazard problem remains.

Still other factors lead me to suspect that the moral hazard problem under the fixed commission system may not be as significant as it first appears. The simple model above ignores the intertemporal dimension to agent effort and the fact that agents in reality expend modest amounts of effort sequentially to purchase draws from distributions. Many of these sequential effort decisions might be better thought of not as a choice of $e$ on a continuum, but as a discrete choice (do I show the house to this buyer or not?). Such expenditures of effort are typically small, and it is plausible to imagine that most worthwhile efforts will be undertaken even under a system that offers the agent a low "marginal" commission.

Further, many aspects of sales effort - the number of showings, ads in the paper, open houses, and the like-are readily observable by the principal and can be explicitly or implicitly specified in the contract. Agents also no doubt exhibit considerable concern for their reputation as sellers, an obvious though extremely important point.

I do not mean to overstate the case, however, and it is surely too bold a claim to suggest that no moral hazard arises under the fixed percentage commission system. Indeed, if incentives for selling effort at the margin are unnecessary to reduce moral hazard, why not a flat fee? This point is well taken, although I cannot help but wonder whether agency problems are the primary explanation for the choice of the fixed percentage over the flat fee. Conceivably, fixed percentage commissions simply afford a convenient rule of thumb for calculating a sales commission that is optimally proportional to value for reasons other than moral hazard identified by previous writers.

\section{The Explanation for Uniformity in Commissions}

It is certainly mistaken to suppose that every residential transaction is governed by a 6 percent commission, but in many markets that arrangement prevails for all but a few transactions. This striking degree of uniformity in commissions, despite the intuition that some properties are much easier to sell than others, is another of the puzzles addressed by Levmore.

Levmore's explanation for uniformity relates primarily to conflicts among principals that would arise in its absence. In particular, he argues that uniform commissions are jointly optimal for all principals collectively 
because it avoids the problem of agents devoting excessive effort to the sale of properties where the marginal commission is higher. He acknowledges difficulty in explaining how such a jointly optimal arrangement would arise in equilibrium or would be protected against defectors but suggests that poorly understood market forces may nevertheless lead to convergence on the efficient outcome. In this section, I wish to offer some criticisms of Levmore's hypothesis and, very tentatively, to suggest another.

It is instructive to begin with a model that illustrates the conflict problem which Levmore addresses and how uniform commissions might eliminate it. Suppose that all principals are concerned solely with the maximization of expected sales revenue and all parties are again risk neutral. Assume further that the principals have no reservation prices and that the value of the properties in their current use is zero. A single agent represents multiple principals. Selling effort devoted to the ith property is $e_{i}$, which by assumption cannot be specified contractually. The expected best offer on the $i$ th property is equal to $R_{i}\left(e_{i}\right)$. The cost per unit of agent effort is $c$, but the agent can only supply a total of $E$ units of effort. The joint optimum for the principals and agent is then for the agent to allocate selling time to maximize $\Sigma_{i}\left\{R_{i}\left(e_{i}\right)-e_{i} c\right\}$ subject to the constraint $\Sigma_{i} e_{i} \leq E$. Assume that this constraint is binding. Then, the joint optimum simply requires the agent to allocate scarce selling time so that the expected marginal revenue per property is the same for all properties. With a uniform, fixed percentage commission of $\alpha$ on every property, the agent chooses the $e_{i}$ to maximize $\Sigma_{i}\left\{\alpha R_{i}\left(e_{i}\right)-e_{i} c\right\}$ subject to the constraint $\Sigma_{i} e_{i} \leq E$. It is easy to verify that as long as $\alpha$ is large enough to induce the agent to exhaust all available time, the solution to this private problem will correspond to the solution to the joint problem when the time constraint is binding. Likewise, without uniform commissions, the agent will not allocate time so that marginal expected revenue is the same on all properties. Under the assumptions here, therefore, Levmore would be right to suggest that uniform commissions efficiently eliminate distortions in the allocation of effort across properties.

Of course, this model does not suggest why all agents would charge the same commissions to all principals, only why a single agent would charge the same commission to all. It thus allows for variation in the commission across agents. Levmore conjectures that similar concerns are at work on the buyer's side of the market, however, whereby uniform commissions on all properties allow buyers the security of knowing that their selling agent will receive the same commission on two properties of the same price and will thus have less incentive to conceal market options or hide other information. Another explanation would simply be that 
competition among agents for listings forces the uniform commission down to the break-even level for the marginal agency. In any case, this model does suggest an interesting virtue of uniformity of the sort that Levmore identifies.

The statement of the model, however, immediately suggests several reasons to question how much descriptive power it has. First, the assumption that principals care only about expected sales revenue is dubious. Some principals will have an urgent need to sell, others are just testing the market (formally, they have different discount rates). The allocation of selling effort that uniform commissions will produce seems entirely insensitive to these concerns.

Second, the depiction of the agent's private problem and the joint problem in the model here are suspect for the reasons discussed in the previous section. The agent operates subject to the principals' reservation prices, which may well drive the agent to effort levels that do not equate the marginal expected revenue times the commission rate across properties. Further, there exists a wedge between the lowest offer that yields joint gains and the lowest offer that a principal will accept ( $K$ vs. $B$ in the model of Section $I$ above). Under a proper representation of both the joint problem and the agent's private problem therefore, any general correspondence between the private optimum with uniform commissions and the joint optimum with a binding time constraint disappears.

Finally, even granting for a moment the questionable formulation of the joint and private problems above, the correspondence between the joint optimum and the private optimum arises only when the constraint on selling time is binding. If selling time is elastically supplied at a cost of $c$ per unit, for example, the agent's private problem reverts to a solution exhibiting the severe moral hazard discussed earlier. There is little reason to expect principals to respond uniformly to that problem with a fixed percentage commission, or at least the discussion then comes full circle to the issues addressed in Section I above. For without the binding time constraint in this model, uniformity no longer serves to resolve a conflict of interest across principals because the conflict evaporates-each principal can obtain as much selling time as desired without having any impact on the ability of other principals to purchase selling time. Concomitantly, even if we assume that simple linear fee schedules are necessitated by transaction costs or other considerations, a joint optimum for all principals and agents absent a binding time constraint would not in general require uniformity of the linear fee schedules.

Given the relative ease of entry into real estate sales, it seems unlikely that constraints on agents' time would be prevalent in the market very often. Perhaps in tight markets the problem might arise, but I find it 
unlikely that such constraints could explain the prevalence of the 6 percent commission over time and space.

To Levmore's credit, he does not rely exclusively on the proposition that uniform commissions generate an efficient allocation of sales "effort" but argues that other aspects of agents' behavior generate conflicts that uniform commissions may reduce. In particular, he suggests that uniform commissions also avoid distortions in the agents' choice of the order in which to sell properties, in the subset of properties to be shown, or in the comparative comments that agents make about them. Each of these points relate, not to the effort supplied by agents, but to their incentives for revelation of private information. My own view is that such incentives may indeed be important to the explanation of uniformity, but that at this stage the matter remains conjectural.

It might well be possible to articulate a model in which uniform commissions generate an optimal order of showings or an optimal subset of properties to show. Conceivably, absent uniform commissions, real estate agents might try to conceal the existence of an available property in the hope that the buyer will purchase one that yields the real estate agent a higher commission. The possibility of allocative losses from the suppression of information about the choice set is obvious. Buyers could assuredly evolve counterstrategies, such as asking to look at a multiplelisting printout for a given price range or reading the classified ads, but these might be imperfect. It is hardly clear that uniform commissions solve the problem altogether, of course, because agents may wish to limit the buyer's choice set simply to economize on the agent's (costly) selling time, with or without uniform commissions. But perhaps uniformity in the commission structure is helpful in lessening the problem.

The allocative effects of "comparative comments" also warrant further consideration, although there are perhaps reasons to doubt their importance. Puffery presumably has little allocative effect, and representations about factual matters such as the quality of local schools, the age of the furnace, and the like can be verified cheaply and independently (independent home inspections, for example, are routine). False statements of material fact may constitute fraud and thus be discouraged whatever the commission structure. Further, even granting an assumption that real estate agents may color their comments in a way that affects the behavior of buyers, it is not obvious that uniformity in commissions produces anything like "optimal commentary"-perhaps the agent's incentive with uniform commissions is to make a sale as quickly as possible to earn the given commission with a minimum of sales effort, and commentary will invariably be distorted toward that end. Nevertheless, one might be able to articulate a model in which a uniform commission structure cre- 
ates less distortion in the incentives for selling agents to reveal allocatively important private information than a nonuniform structure. ${ }^{3}$

There is another possible source of allocative gain from uniformity that Levmore does not consider. Again, it relates to the incentives for information revelation, this time on the sellers' side of the market. Imagine that real estate agents draw buyers from different distributions. Consequently, for any given property, the expected best offer varies across real estate agents. Imagine further that real estate agents know the distribution of buyers from which they will draw offers, but sellers do not. Finally, assume that real estate agents all incur the same costs of servicing a listing. ${ }^{4}$ Thus, the allocative problem is a simple one-to link each seller with the real estate agent who brings the highest expected best offer to the transaction, when that information is unknown to the seller.

Quite plausibly, the fact that commissions are uniform across real estate agents may facilitate the proper matching of sellers and real estate agents. The argument begins with the proposition that real estate agents may influence their client's reservation prices through the information that they convey when they are competing for the listing. The more optimistic they sound, the higher the resulting reservation price is likely to become. Under some conditions, uniform commissions can then ensure that the real estate agent who sounds the most "optimistic" in competing for a listing is the real estate agent with the best distribution of buyers for the property in question, and the seller can rationally choose a real estate agent on that basis. With nonuniform commissions, by contrast, the most "optimistic"'-sounding real estate agent may simply be the one who receives the higher commission in the event of a lucky draw from its distribution. A real estate agent's "optimism" then reveals little about that real estate agent's sales prospects.

Consider the following illustration, which I concede to be grossly simplistic and suggestive only. Suppose that sellers set their reservation prices at some constant fraction, $r$, of the price at which their property is listed, $L$ (a seller might decide to accept any offer equal to 95 percent of the listing price, for example, but not less). Real estate agents know that sellers behave in this fashion and offer advice to their clients about

\footnotetext{
${ }^{3}$ Levmore also suggests that uniform commissions may eliminate distortion in the agent's decision to sacrifice leisure in order to engage in selling. Perhaps I am misunderstanding or missing the point, but this claim seems mistaken in general. Even in the oversimple model in the text, for example, there is no distortion that is solved by uniform commissions absent a time constraint.

${ }^{4}$ This assumption is not utterly implausible. Between reputational concerns and the fact that the client can insist on certain observable sales measures such as ads in the paper, open houses, and the like, the direct costs incurred over the course of a listing agreement may be quite comparable across real estate agents.
} 
the choice of $L$. We restrict attention to the set of sellers who would be willing to accept an offer at that price given the commission paid and the value of the property in its current use. Everyone is risk neutral.

Assume that real estate agents all have the same costs of servicing a listing, $c$, which they must incur even if no sale is made. They are paid a fixed percentage commission, call the percentage $\alpha$, and are willing to accept a listing as long as the expected commission, which obviously depends on the seller's reservation price $r L$, is at least equal to $c$. For any distribution of expected best offers where the best offer may be below the reservation price, the expected commission obviously declines as the reservation price rises so that, other things being equal, real estate agents prefer a lower listing price. But real estate agents must compete for listings with other real estate agents, and we seek to show that, with uniform commissions, sellers can rationally choose between real estate agents according to who recommends the highest listing price.

To complete the illustration, it suffices to consider two real estate agents, each of whom can draw a best offer, $S$, from a uniform distribution of buyers at the cost $c$. Real estate agent 1 has a best offer distribution that is uniform on $[a, b]$, while real estate agent 2's distribution is uniform on $[x, y]$, where $x>a$ and $y>b$. Thus, real estate agent 2 has the highest expected best offer and is the best choice to list the property. For simplicity, let $y-x=b-a$, although this is inessential.

Real estate agent 1 will not recommend a listing price so high that the expected return to the listing is negative. Thus, real estate agent 1 will not recommend a listing price in excess of the $L$ that satisfies

$$
\int_{r L \leq S \leq b}\{\alpha S /(b-a)\} d S=c .
$$

Performing the integration, real estate agent 1 's maximum recommended listing price, $L_{1}$, is equal to $\sqrt{\left(\left[\alpha b^{2}-2 c(b-a)\right] / \alpha r^{2}\right)}$. Real estate agent 2 's maximum recommended listing price, $\mathrm{L}_{2}$, is similarly computed as $\sqrt{\left(\left[\alpha y^{2}-2 c(y-x)\right] / \alpha r^{2}\right)}$. Using prior assumptions, it is clear that $L_{2}>$ $L_{1}$, so that if the real estate agents are "bidding" against each other for the listing, real estate agent 2 will prevail. Omitting the algebra, it is also straightforward to verify that, if real estate agent 1 receives a larger commission than real estate agent 2 , say $\beta S$, where $\beta>\alpha$, then real estate agent 2 may no longer "bid" the most for the listing even though real estate agent 2 has a superior distribution of buyers.

To be sure, not only have I not shown with a high level of generality that uniform commissions induce truthful revelation of information in the "bidding" process, but this result assuredly does not hold in general. Departures from the assumption that real estate agents have the same costs can destroy it, for example, and it certainly will not hold for arbi- 
trary distributions of expected best offers. The illustration is also troubling for the fact that the seller's reservation price is assumed a fixed percentage of the listing price without any effort to justify such a rule of thumb as rational. Nevertheless, it seems plausible that the prevalence of a standard commission facilitates negotiations between sellers and real estate agents by diminishing the incentives for real estate agents who receive higher commissions to exaggerate sales prospects. Even if the incentives for real estate agents to be truthful are by no means ideal under uniform commissions, therefore, they may be better.

More generally, this illustration supports the earlier claim that uniformity may have valuable effects on the incentives for real estate agents to reveal private information. For the reasons developed above, such incentives seem a more likely source of a convincing explanation for the uniformity of commissions in residential real estate sales than incentives relating to the allocation of costly sales efforts across properties. To the extent that Levmore tends to emphasize the latter rather than the former, I suspect that his emphasis may be misplaced. 
HeinOnline -- 36 J.L. \& Econ. 5521993 